\title{
AN APPRAISAL OF THE HEALTH PLANNING METHOD PROPOSED BY THE PAN AMERICAN HEALTH ORGANIZATION FOR LATIN AMERICA *
}

\section{RSPSP-145}

Araújo, J. D. de - An appraisal of the health planning method proposed by the Pan-American Health Organization for Latin America. Rev. Saúde públ., S. Paulo, 6:305-15, 1972.

Summary: A brief description of the main features of the health planning technique developed by the "Centro de Estudios del Desarrollo" (CENDES) in Venezuela, and proposed by the PanAmerican Health Organization for use in Latin America, is presented. This presentation is followed by an appraisal of the planning method which includes comments both upon its positive aspects and upon its negative points. Comments are also made referring to other recent publications of the WHO/PAHO on health planning. In conclusion, the CENDES technique is considered a health planning method of great potential for ise especially in underdeveloped areas, the success of its application depending upon the hability of the health planners to introduce the necessary modifications to adapt to the local circunstamces.

UNITERMs: Health and welfare planning*; Pan-American Health Organiza tion *; Latin America*.

\section{I N T RODU CTION}

In August 1961, on a meeting of the Economic and Social Council of the Organization of American States, in Punta del Este (Uruguay) it was approved a document considered a landmark in the history of Latin America: "The Charter of Punta del Este" 2. In this document great emphasis was given to health as an important component of overall development. A specific recommendation was then made that national health plans should be prepared for the Latin American Countries in the following decade. In addition to that, the Pan-American Health Organization (PAHO) was formally charged with the responsability to help the national planning units, and also requested to develop adequate health planning methods for Latin America.

In 1965, the PAHO published a Health Planning monograph prepared by the "Centro de Estudios del Desarrollo (CENDES) de la Universidad Central de Venezuela". 6. This document has ever since been referred to, among health planners and administrators, as the "CENDES planning method". It has also been largely used as a planning guide by the majority of the Latin American countries.

Our main purpose in this article is to appraise the CENDES planning method. However, considering the fairly long time elapsed since its introduction, we tried to obtain additional information on the progress made by the PAHO and

* This paper was written at the University of California, in Berkeley, while the author was under a fellowship of the World Health Organization. The ideas expressed in the article are the responsability of the author and not of the sponsoring Organization.

* From the "Departamento de Medicina Preventiva, Faculdade de Medicina da Universidade Federal da Bahia - Vale Universitário, Canela - Salvador, Bahia, Brasil". 
ARAUJJO, J. D. de - An appraisal of the heaith planning method proposed by the Pan_Ameri. can Health Organization for Latin America. Rev. Saúde publ., S. Paulo 6: 305-15, 1972.

by the World Health Organization (WHO) as well, in the field of health planning.

As a consequence, additional comments will be made on some more recent documents dealing with the same subject, such as, the WHO technical reports on statistical indicators for health planning 7 and on training in national health planning, 8 and the guidelines for the preparation of quadrennial health programs for the American countries, 5 recently revised by the PAHO in Washington.

\section{SUMMARY DESCRIPTION OF CENDES' PLANNING METHOD}

The CENDES' planning method 6 will be briefly described in order to provide a basis for subsequent analysis.

\section{A. Basic planning principles}

The necessity of planning arises whenever you have to decide upon a problem that may be resolved in different manners (choice of techniques) and/or when you have to decide among different objectives (choice of priorities). Because of the practical constraint represented by the limitation of available resources for health programs, the choice must lead to a combination of efforts which provides a maximum amount of health with a given amount of resources or, inversely, if you intend to attain a given level of health, to a combination of efforts that could lead to it, with a minimum of expenditures.

A clear definition of objectives constitutes a basic principle for the planning method. The objectives should be quantitatively described and as such are called "targets".

Because of the variety of objectives within any proposed health program, they should ideally be reduced to a common denominator to allow for comparison.
The definition of the basic objectives of health activities is made difficult by the lack of adequate health indicators.

The concept is advanced of "Years of Productive Capacity" (YPC), which gives different values to the life of persons of different ages, to be discarded in favor of the opinion that any human life is equal to another and that morbidity and mortality cannot be reduced to a common denominator.

The resources for health however must be reduced to a common denominator which is money value. Moreover, resources should be combined in determined proportions to constitute the "instruments" used reach a given objective. This process is called "instrumentalization of resources".

The selection of a combination of techniques that gives the better yield in relation to costs is considered one of the most important tasks of the health planner.

Health activities are considered as the Government actions oriented towards health maintenance. The planning process should encompass all aspects of these activities. In addition to that, planning should be future oriented: health plans should cover periods of 5 to 10 years. Also a spacial dimension should be considered: the area to be covered by the plan; within its defined boundaries, the principle of distributive justice determines that all population groups are to be considered, regardless of cost benefit analysis, but within reasonable limits.

\section{B. The planning process}

Health planning comprehends the following steps that will be separately considered: 1) diagnosis; 2) planning as such; 3) discussion and decision; 4) execution; and 5) evaluation and revision. 
ARAUJO, J. D. de - An appraisal of the health planning method proposed by the Pan_Ameri. can Health Organization for Latin America. Rev. Saúde públ., S. Pauio 6: 305-15, 1972.

The planning process should lead to the formulation of propositions meeting three basic conditions: to be viable, internally compatible and efficient.

\section{Diagnosis}

The assessment of the health situation in the area for which one is planning should encompass the following points:

1. a quantitative description of the health situation in the chosen area;

2. the determinant factors of the given situation;

3 . the analysis of its perspectives;

4. an appreciation of whether or not the situation is considered satisfactory.

An important part of diagnosis is the definition of the "programming area" using the criteria of population, communications and concentration of health facilities and administrative services. The country should be divided in "local programming areas" and a certain number of local areas will constitute a "Regional programming (or planning) area". The planning process should always start at the local area.

The description of the health situation includes the following aspects: a) the hazards to health (diseases); b) available resources and current health activities; c) allocation of financial resources to different uses; d) unit cost of the various health activities; e) the population; and $f$ ) the milieu (environment).

In order to decide which diseases are prioritary they should be evaluated according to their magnitude, their social importance (transcendence) and their vulnerability to preventive methods. Weights are given to each of these criteria and the diseases are ranked by a numerical score. The most important step however is to determine how much is spent in the attack to each disease ("daño" in the Spanish original), and then to figure out which is the cost of each prevented death, for any of the so-called "reducible" (preventable) diseases, or which is the cost of each recovered case for any of the so-called "non reducible" diseases.

The available resources are grouped in instruments, tasks and techniques. To combat a disease each instrument accomplishes a task and a given combination of tasks constitutes a technique (e. g. prevention or treatment).

The cost of each technique is determined and compared with the results of its application. The final result is the cost of attack to each disease (preventive actions and curative actions) expressed in monetary units per prevented death, as already metioned.

The description of the situation includes also standard demographic data as well as informations regarding environmental factors such as housing, water supply, sewage and refuse disposal, food hygiene, vectors, industries and schools. An attempt should be made to explain the present health situation identifying causal or determi. nant factors (demographic, environmental, social, political or economic).

The next step is the prognosis for the health situation if no modifications are introduced in the near future.

The final part of the diagnosis is a consideration of whether or not the present situation is satisfactory as judged objectively by the planner.

\section{Determination of alternatives in the local programming area}

After the formulation of a careful diagnosis the local planner is faced with the following questions:

a) What amount of resources is going to be allocated to the plan? 
ARAúJO, J. D. de - An appraisal of the health planning method proposed by the Pan_Ameri. can Health Organization for Latin America. Rev. Saúde públ., S. Paulo 6: 305-15, 1972.

b) Which diseases should receive priority? and

c) Which are the best techniques to use?

The method suggests that the planner should start by the questions " $b$ " and " $c$ " setting the priorities according to the criteria of magnitude, importance and vulnerability. These priorities are then translated into "targets" and "objectives" with the corresponding combination of tasks, instruments and techniques and their respective costs. The local plan should include one maximal alternatives, either on a natioves, to be applied depending upon the economic constraints set in question "a".

\section{E. Formulation of regional and national health plans}

Since usually the limited resources do not allow for the application of the maximal alternatives, either on a national or even on a regional scale, it is the crucial responsability of the regional and national planners to elaborate the intermediate alternatives, initially for the local programming areas, then for each region and ultimately for the nation as a whole.

The regional planner must set programs for these areas too remote and scarcely populated that could not be included in the local programs.

Special programs are also set by the national planning authority for these diseases that strategically need to be attacked on a nationwide basis (smallpox erradication campaigns for instance).

The national planning authority should consider especially the needs for manpower resources and its training. The plans of capital investment (new buildings, expanding of facilities etc.) should be considered and decided at the national level.

It is the ultimate responsability of the national planner to allocate resources to each planning region. Ideally this should be done by the programming budgeting technique (PPBS).

\section{F. Decision, execution and evaluation}

After the discussion of the health plan with the national authority in charge of the overall Government plan, comes the critical step of political decision, where the participation of the health planner is mainly to provide information for the decision-making body (Legislative and/or Executive Power).

It is considered that the success in the execution of the plan is intimately related to the degree of participation that those responsible for its implementation had in the preparation of the plan at the local level.

The planners should have a vital in terest in control and evaluation of the execution of the plan in order to obtain the informations necessary for the revision or re-adjustment of the plan which should be made every year.

\section{ANALYSIS OF THE CENDES' PLANNING METHOD}

The CENDES' technique may be seen as a combination of problem solving and allocative planning with the possibility of inclusion of some normative planning in its body of concepts and method as future oriented, the economic tions. Though one can consider the method as future oriented, the economic conditions under which it is often applied make the planners to use it mainly as a device for better allocation of resources aimed at the solution of the most immediate health problems.

It is our intention to appreciate 
ARAUJO, J. D. de - An appraisal of the health planning method proposed by the Pan.Ameri. can Health Organization for Latin America. Rev. Saúde puibl., S. Paulo 6: 305-15, 1972.

separately what we consider the positive aspects and the negative aspects of the method. The basis for this criticism will be twofold: first, a theoretical frame of reference represented by the publication of BLUM 1 on health planning, and second, a recent personal experience resulting from being exposed to the CENDES' methodology during work in health administration in Brazil, from 1967 to 1971.

\section{A. Positive aspects of the CENDES' method}

In our opinion the existence of the method per se, and its wide utilization in Latin American countries during the last decade, speak strongly in its favor. Whatever are the critiques made to the technique, and we ourselves will be presenting some serious ones, the fact that the CENDES' method has brought to many countries a possible way to rationalize a field of chaotic and uncoordinated health activities, is in itself a great merit.

It is true that health planning activities already existed in Latin America before the CENDES' method. However, it was the introduction of the new methodology which brought the widespread interest in health planning the beginning of courses to train health planners, and finally the acceptance, both by the health administrators and by the Governments themselves, of the fact that health planning is an important component of the measures aimed at promoting economic development and social welfare.

This acceptance of the method, however, did not happen by chance nor was it imposed by force of authority: it resulted from positive qualities of the method which deserve some separate comment.

a) Rationality. The method is struc- tured as a logical sequence of steps, one resulting naturally from the antecedent, in a manner that not only is appealing to the analytical mind, but is easy to grasp and difficult to contest. As a mater of fact, the components of the technique are in general encountered in most of the health planning modes that we examine nowadays, but he way in which they were arranged by CENDES is almost unique in the rationality of its sequence, as well as of the relationships among the parts of the system and the levels of activity.

b) Simplicity. Though at a first approach the question of instrumentalities, and also the set of criteria to establish priorities among health problems (diseases), seem complicated and perhaps confusing, in practice its application is of extreme simplicity and its use can be rapidly mastered even by the less sophisticated components of the planning teams. This is certainly not a minor advantage when one considers the fact that this is a planning method designed for application in underdeveloped countries where there is a serious shortage of personnel trained to deal with more sophisticated instruments.

c) Ecological approach. The method makes a point of considering the health situation as a result of a multiplicity of determinant factors to be sought in the environment (physical, socio-cultural and economic) in addition to the traditional "direct" causal factors of diseases (microorganisms, nutritional deficiencies etc.). This approach is a positive step in the direction of recognizing the link between health status and the level of social and economic development. It is also an appropriate instrument for the selection of the adequate interventions which very often must be directed to factors outside the health field. Here we must introduce a word of caution: the area of diretct influence of the health 
ARAuJO. J. D. de - An appraisal of the health planning method proposed by the Pan.Ameri. aan Health Organization for Latin America. Rev. Saude pribl., S. Paulo 6: 305-15, 1972.

planneri s the health field and whenever he suggests intercentions outside of this field his chances of getting his plans implemented are not certain at all. Meanwhile something must be done to alleviate the health situation irrespective of its external causes. In the hands of an astute planner the method leaves room for considering simultaneously both kinds of interventions whenever indicated.

d) Efficacy and efficiency. Through its emphasis on the careful combination of the health resources in instruments designed to perform given tasks, and to achieve given objectives, the method leads necessarily to greater efficacy in the combat of the specific diseases or the solution of a given health problem. On the other hand, the allocation of financial resources to programs selected on the basis of a rigorous cost benefit analysis (the cost of death-prevented criterium leads to increased efficiency in the use of health expenditures). Of course we do not consider efficiency as the major quality of a health plan or program. Nevertheless it cannot be overlooked in underdeveloped countries, where the economic constraints to health activities are a major issue. The use of adequate instrumentalities according to the CENDES' technique is capable by itself of bringing improvement in the health situation, without further expenditures, just by making more efficient (and efficacious) use of the available resources.

e) Health Planning as part of National Development Plans. The fact the health sector is too frequently underconteplated in national economical and/or development plans, results in part from lack of adequate planning of the health activities with a rigorous selection of priorities, and a rational allocation of resources to assure the efficient use of the public investments in the health sector. The use of the CENDES' tecnique gives to the health administrator an instrument to face the economic planners and to make a good case for the inclusion of the health activities in the national development plan and for the allocation of a reasonable (but not exaggerated) amount of financial resources for the health sector.

f) Health Planning and PPBS. A natural sequence to the utilization of the CENDES' method has been the adoption of the program budgeting system (PPBS) with a series of advantages.

When the time comes for the health plan to be appreciated by the decision making political body, there is less possibility of changes being introduced to attend to regional or local political interests, because resources are allocated by programs that cannot be divided apart.

The adoption of PPBS on the other hand makes the health administrator accountable not only for expenditures, as in traditional budgets, but mainly for the execution of programs and production of a predicted output of services. This may facilitate in great part the process of evaluation of the plan's execution.

g) Local planning. The importance given to the local programming areas as the starting point of the whole planning process is one of the major positive aspects of the method. The participation of local authorities in the preparation of the plan is considered by CENDES one factor leading to success in the implementation of interventions. Also, because of the scarcity of statistical information in Latin America, sometimes only by direct survey of the local planning areas it is possible to obtain the data needed to define the problems and set the priorities.

Nevertheless, we must recognize, this positive emphasis on local planning is counterbalanced by two negative points 
ARAUJO, J. D. de - An appraisal of the health planning method proposed by the Pan_Ameri. can Health Organization for Latin America. Rev. Saude puibl., S. Paulo 6: 305-15, 1972.

which will be discussed later: the lack of consumers' participation and the lack of any decision power at the local level.

\section{B. Negative aspects oft he CENDES method}

Despite all the positive aspects that we have just pointed out, the CENDES' method is amenable to some criticism. The negative points that we see in the technique will be pointed out and briefly discussed next.

\section{a) Values and Goals.}

There is in the CENDES' method a conspicous absence of any mention to the role that the system of values of a given community (local area, region or country) should play in the definition of the goals of a health plan. It seems implicit that a broad "health policy" has already been defined for Latin America. Up to some extension that is true, since the Punta del Este Charter established in 1961 some definite health goals to be achieved in the 1960-1970 decade 2 , such as an increase of 5 years in the life expectancy, a reduction of $50 \%$ in the mortality of children less than 5 years old, and the improvement of sanitation (water and sewage) both in urban and rural areas.

In our opinion however, these "continental" goals set by experts of international reputation, valid as they indeed are, do not substitute for a national or regional health policy established on the basis of the socio-cultural values peculiar to each country and to each region.

The prima facie acceptance of a set of policies, established without regard to the values of the community to which they are going to be applied, may definitely contribute to the alienation of the local population and sometimes even of the local health professionals that do not feel committed to goals they did not contribute to define.

This approach of predetermined, experts set, health policy leads necessarily to ignoring the consumers. The consequences of the total absence of consumer participation in the CENDES planning method has very serious consequences that deserve some comments.

Whe have already mentioned the risk of loss of cooperation from the community and sometimes of the health professionals themselves.

The opportunity to get different views of the health problems, and of their relative importance, is lost! As a consequence health issues of major importance, from the community standpoint, may not even be considered by the planners.

Also we want to point out that the minority groups have no way to voice their needs and concerns. Let no one think that this is not problem in Latin America, where many countries have large contingents of indian or black population with their own cultural identities, their set of values, and their deeply feelt needs, too often not met by the prevalent social system.

\section{b) Problem analysis.}

Though the chapter on "Diagnosis" is the more carefully elaborated in the CENDES' method it presents many a point open to criticism.

The emphasis of the method is on the analysis of disease and particularly of death. Even in countries with very high mortality rates, this is a very limited approach to health problems. Important health conditions that are not perceived as illnesses and do not lead to death can be totally overlooked by the planners.

Even if one accepts the "disease 
ARAÚJO, J. D. de - An appraisal of the health planning method proposed by the Pan.Ameri. can Health Organization for Latin America. Rev. Saude pübl., S. Paulo 6: 305-15, 1972.

approach" one has to question the separate analysis of each clinical entity. It seems much more logical to consider groups of diseases with similar determinant factors and susceptible to the same preventive measures. As an example, it is not justified to plan separately for infectious diarrheas, typhoid fever or infectious hepatitis, when all need a single common intervention (namely water treatment and supply) for their adequate prevention. Or, in another example, there is no reason to consider separately diphteria, tetanus and pertussis, when their prevention is obtained by the use of a combined triple (DPT) immunization.

On the other hand, since it is not feasible to analyse all the known diseases, then some degree of arbitrary decision should be made regarding which diseases are to be included in the analysis, and which a critical and delicate endeavour as planning for the health of a population.

The CENDES' emphasis on disease and prevention of death also leaves out of the planing scheme such activities as health education and mother and child health, which are not related to any particular disease but have a major importance in the promotion of good health habits as well as in the prevention of a variety of serious health problems.

The consideration of separate diseases on the other hand, must lead necessarily to overlapping of activities because of the "spillover effect" characteristic of many intervention in the health field. Many measures designed toward a specific disease affect other diseases as well.

The nature of the planning bodies is a decisive factor in the choice of interventions. However, the method does not discuss the composition and the authority of these planing bodies. In our opinion it would have been very important to define these points in order to assure representation of all the interested and responsible sectors of the communities, as well as the necessary political independence of the planning units. The silence in this respect has led to the constitution of purely technical planning bodies, most often directly under the political authority of the executive branch. This limitation stems in part from the state scope of the method that is to plan for the "health activities performed by the Government". Though in Latin America the Government is responsible for the major share of health activities, we believe that this limitation is untenable and speaks against the efficacy of health planning.

Another important point to emerge from the analysis of the process of selection of interventions is that the CENDES method may end up being used as a technique of planning health services, instead of an instrument of planning for health. This would be a very limited application of a most potent and valuable tool.

\section{d) Decision making: Selection of interventions}

This being essentially a political process escapes from the direct influence of the planner. There is however a point we consider of utmost importance and that the method fails to make. We consider that health planning, besides its other uses, should also be employed as a weapon to convince economists, technocrats and politicians, of the need to give a better share of financial resources for health activities, and to include health in the economic development plan. A careful analysis of the issue of integration of the health sector in developmental planning was made by Cівотті $^{3}$ and it deserves the particular attention of health planners in under- 
ARAujo, J. D. de - An appraisal of the health planning method proposed by the Pan_Ameri. aan Health Organization for Latin America. Rev. Saúde pübl., S. Paulo 6: 305-15, 1972.

developed countries. The CENDES method, in this particular, is very passive and just endeavours to make the best out of the little financial resources that may be given to the health sector.

\section{e) Evaluation}

Though stating that the evaluation and control of the plant's execution is a most important step in the planning process, the CENDES' technique fails to present the methodology for evaluation. This is a serious gap because evaluation is without question one of the most difficult tasks in health planning.

\section{Final Comments}

The critiques that have just been made do not mean to negate the value of the method: they should rather be considered as suggestions for changes in the technique, in order to adapt it better for the role that it is supposed to play in helping Latin America countries to improve the health of their populations, and, in this way, contributing to the economic development and social welfare of a whole continent.

\section{COMMENTS ON ADDITIONAL PUBLICATIONS}

Our effort to gather data regarding the application of the CENDES method and its evolution had meager results. Though we are informed that many health plans have been made using the technique, we were unable to find them published in the current medical literature, except for a single report on the health planning for a local programming area in northeast Brazil 4. This report has the merit to show that you can use the CENDES' method, with adaptations, in underdeveloped areas, with poor statistics and little resources.

We obtained a copy of the document
"Guidelines for the Formulation of the Quadrennial Projections of PAHO/WHO Program of Cooperation with the Countries of America" 5, that seems to be the most recent publication of PAHO regarding health planning for Latin America and can be examined as a complement of the CENDES' technique.

The "Guidelines" have a definitely limited scope: the formulation of plans to be submitted to PAHO in order to obtain external cooperation (technical or financial aid). This limitation of scope brings the risk of substituting the prepaartion of programs aimed at international assistance in the health field

for true national health planning. Programs of international assistance will have little if any sucess without serious national planning.

In general, the "Guidelines" recommend a methodology very similar to the CENDES' technique, with more emphasis on the use of systems analysis, what represents a definite progress.

Another progress to be noticed is the inclusion in the plans of the provate sector, which had been left out by CENDES. Also the "Guidelines" tackle the issue of the composition of the planning bodies; however, they envision a purely technical planning group, really non representative of the wide variety of concerns and interests in the health field. The experts' approach of CENDES is not modified.

Though the 4 years projections represent an effort in forecasting they are constructed upon data that by more rigorous standards would not allow for valid forecasting. It seems strange to establish projections to 1974 (and sometimes even to 1980) based only on data from 1970, without at least the benefit of a series of data from 4 or 5 previous years, as the basis to establish 
ARAUJO, J. D. de - An appraisal of the health planning method proposed by the Pan_Ameri. can Health Organization for Latin America. Rev. Saude pribl., S. Paulo 6: 305-15, 1972.

any trends. It should be remarked that their approach to budget is traditional, instead of recommending programbudgeting.

Despite these criticisms we put a high value in the "Guidelines" as a first step towards international health planning for Latin America. If all the member countries submit annually their "projections", the PAHO will find itself in a privileged and unique situation of being able to grasp the health problems of a whole continent and to exert, within the limitations of its powers, a great influence not only orienting coordinated efforts for the solution of common health problems, but also channeling the necessary financial support wherever the magnitude of the problems exceedes a given countrys economic possiblities.

The WHO Experts Committee prepared two recent technical reports 7,8 that though not directly related to the CENDES' method are very relevant for those interested in its application in Latin America.

The report 8 before going into the details of the preparation of planning personnel, makes some very important points that must be taken into account in this analysis.

Though recognizing that health planning must be progressively developed in each country, the report 8 states that "it is both possible and necessary to construct, a general model of a comprehensive health planning system, whether health planning is carried out in developed or developing countries, whether the form of political organization is centralizes or decentralized, whether the constitution provides for unified, federated or confederated government, whether the immediate problems are at the level of basic health services, or the control of costs in sophisticated medical situations, and whether the most urgent requirements are to develop resources or to improve the use of available resources".

This report also emphasizes the fact that "the health system and the health planning subsystem are linked with other sectors of society concerned with socio-economic development and the quality of life".

The most important point to mention in this report, however, is its preoccupation with consumers' participation in health planning. This represents a remarkable departure from the traditional experts' approach taken by the international health organizations.

The most recent report 7 deals with the difficult problem of how to provide health planners with statistical information relevant to their needs. This report also elaborates on the nature and basic principles of the health planning methodology but puts its emphasis on the analysis of the type of information necessary for the adequate performance of each the functions implicit in the planning process.

A sharp critique is made of the current statistics available to planners, and a considerable effort is made to define what are the real needs of the planners and which statistical system should be devised to fulfill these peculiar needs.

For the particular situation in which the CENDES' method is being used in Latin America the most important contribution of the report 7 is contained in its statement: "Planning methods can be related realistically to the information systems available, and the introduction of sophisticated techniques of health planning postponed until a long term plan has been developed for the simultaneous introduction of advance health information systems". 
ARAUJO, J. D. de - An appraisal of the health planning method proposed by the Pan-Ameri. can Flealth Organization for Latin America. Rev. Saude públ, S. Paulo 6: 305-15, 1972.

The publications, that we have just commented upon, are a testimony of the permanent interest of the international health organizations in planning, and of their efforts towards improving the health planning methods and systems in operation all over the world. The development and perfectioning of adequate techniques is a continous, dynamic process, as planning itself should be. When we consider the history of this process in Latin America we can conclude that the CENDES' planning method represented a major contribution to national health planning. Its potential for future useful application depends entirely upon the ability of its users to evaluate and revise the technique, under the light of the most recent contributions to the philosophy and methodology of health planning that are proceeding from the efforts of experts in different parts of the world.

\section{RSPSP-145}

Araújo, J. D. de - [Uma apreciação do método de planejamento de saude proposto pela Organização Panamericana da Saúde para a América Latina]. Rev. Saúde públ., $S$. Paulo, 6:305-15, 1972.

Resumo: Foram descritos os principais aspectos da técnica de planejamento de saúde desenvolvida pelo "Centro de Estudios del Desarrollo" (CENDES) na Venezuela e proposta pela Organização Panamericana da Saúde para uso na América Latina. Foi feita análise da técnica de planejamento incluindo comentários tanto sobre os seus aspectos positivos como sobre suas limitaçóes. Foram referidas algumas publicações recentes da OMS/OPAS sobre plancjamento de saude. Conclui-se que a técnica CENDES é considerada como uma metodologia de planejamento de saúde de grande potencial para uso especialmente em regiões em desenvolvimento, depen- dendo o sucesso na sua aplicação sobre tudo da habilidade dos planejadores, em introduzir as modificações necessárias à sua adaptação às condições locais.

UnITERMos: Planejamento*; Saúde*; América Latina. Organização Panameri. cana da Saúde*.

\section{REFERENCES}

1. BLUM, H. L. - Health planning 1969. San Francisco, American Public Health Association, Western Regional Office, 1969.

2. CARTa de Punta del Este. Bol. Ofic, sanit. panamer., $51: 477-93,1961$. en la planificación del desarrollo. Bol

3. CIBOTTI, R. - La integración del sector salud en la planificación del desarrollo. Bol Ofic. sanit. panamer., 66:93-105, 1969.

4. CostA, L. T. da, et al. - Planejamento de saúde em área programática brasileira. Bol. Ofic. sanit. panamer., 67:281-91, 1969.

5. GUIDELINES for the formulation of the quadrennial projections of PAHO/WHO program of cooperation with the countries of America. Washungton, D.C., Pan_American Health Organiza. tion, 1971. [Revision 1]

6 UNIVERSIDAD CENTRAL DE VENEZUT. LA. Centro de Estudios del Desarrollo. - Health planning. Problems of concept and method. Washington, D.C., Pan-American Frealth Organization, 1965. (PAHO - Scientific Publica tion, 111).

7. WORLD HEALTH ORGANIZATION. Expert Committee on Health Statistics. Statistical indicators for the planning and evaluation of public health programmes: 14th report. Geneve, 1971. [Techn. Re. Ser., 472]

8. WORLD HEALTH ORGANIZATION. EXpert Committee on Training in National : Health Planning - Report. Gene. va, 1970. [Techn. Rep. Ser., 456].

Received for publication in 19-9-1972

Approved for publication in 25-10-1972 